\title{
Decellularization of pericardial tissue and its impact on tensile viscoelasticity and glycosaminoglycan content
}

\author{
Birzabith Mendoza-Novelo , Eva E. Avila , Juan V. Cauich-Rodríguez , Eduardo Jorge-Herrero . \\ Francisco J. Rojo , Gustavo V. Guinea , José L. Mata-Mata \\ Departamento de Química, Universidad de Guanajuato, Noria Alta sfin, 36050 Guanajuato, Gto, Mexico \\ Departamento de Biologí, Universidad de Guanajuato, Noria Alto s/n, 36050 Guanajuato, Gto, Mexico \\ Centro de investigación Científica de Yucatán A.C. Colle 43 No. 130. Col. Chuburná de Hidalgo. 97200 Mérida. Yucatán. Mexico \\ Hospital Universitario Puerta de Hierro, Servicio de investigaciones Quirúrgicas, cf Manuel de falla 2, 28222 Majadahonda, Madrid, Spain \\ Depatamento de Ciencia de Materiales, E.TS.I. de Caminos, Canales y Piertos, binversidad Politécnica de Madizi, c/ Profesor Aranguren s/n, 28040 Madrid, Spain
}

Keywords:

Tissue decellularization

Pericardium

Glycosaminoglycans

Tensile properties

Detergents

\begin{abstract}
A B S T R A C T
Bovine pericardium is a collagenous tissue commonly used as a natural biomaterial in the fabrication of cardiovascular devices. For tissue engineering purposes, this xenogeneic biomaterial must be decellularized to remove cellular antigens. With this in mind, three decellularization protocols were compared in terms of their effectiveness to extract cellular materials, their effect on glycosaminoglycan (GAG) content and, finally, their effect on tensile biomechanical behavior. The tissue decellularization was achieved by treatment with $t-0 c t y l$ phenoxy polyethoxy ethanol (Triton $X-100$ ), tridecyl polyethoxy ethanol (ATE) and alkaline treatment and subsequent treatment with nucleases (DNase/RNase). The quantified residual DNA content $(3.0 \pm 0.4 \%, 4.4 \pm 0.6 \%$ and $5.6 \pm 0.7 \%$ for Triton $X-100$, ATE and alkaline treatment, respectively) and the absence of nuclear structures (hematoxylin and eosin staining) were indicators of effective cell removal. In the same way, it was found that the native tissue GAC content decreased to $61.6 \pm 0.6 \%$, $62.7 \pm 1.1 \%$ and $88.6 \pm 0.2 \%$ for Triton $X-100$. ATE and alkaline treatment, respectively. In addition, an alteration in the tissue stress relaxation characteristics was observed after alkaline treatment. We can conclude that the three decellularization agents preserved the collagen structural network, anisotropy and the tensile modulus, tensile strength and maximum strain at failure of native tissue.
\end{abstract}

\section{Introduction}

Bovine pericardium is a collagen-rich biological tissue widely used as biomaterial in the construction of a variety of bioprostheses such as heart valves [1-3], vascular graft [4-6] and patches for abdominal or vaginal wall reparation $[7,8]$. However, despite relevant advances, some complications have been found in these bioprostheses such as the biological matrix deterioration and tissue degeneration associated to mineralization $[2,9]$. In order to overcome these limitations, biological materials have been decellularized in different manners and suggested for their use in tissue engineering applications as scaffolds, where the matrix serves as structural support, cell attachment site and reservoir for signaling factor for the resulting tissue remodeling [10-14].

It has been known that pericardial tissue contains almost entirely type I collagen arranged hierarchically in different levels of organization with various structures, such as fibrils, fibers, fiber bundles and laminates [15,16]. These structural features of pericar- djal tissue confer on it a non-linear and anisotropic mechanical behavior [17]. Bovine pericardium also can be called a multi-laminate composite pliable material because it consists of a network of collagen and elastic fibers embedded in an amorphous matrix, which in turn is composed mainly of free glycosaminoglycans (GAGs) and proteoglycans (GAGs linked to protein cores) $[18,19]$.

Different approaches have been reported as effective procedures to remove cells from pericardial tissue with the aims of removing cellular antigens and procalcific remnants while extracellular matrix (ECM) integrity is preserved as much as possible $[20,21]$. The combination of chemical, physical and enzymatic methods destroys cell membrane and removes any nuclear and cellular material $[3,20]$. The remaining acellular ECM will be a complex mixture of structural and functional proteins, glycoproteins and glycosaminoglycans arranged in a three-dimensional architecture $[13,22]$. However, some alteration in the acellular ECM mechanical and structural characteristics can be induced during the decellularization process [20]. In this regard, bovine pericardium decellularization with sodium dodecyl sulfate, an anionic detergent, caused irreversible swelling, denaturation and a drop in tensile strength compared to native tissue $[21,23,24]$. 
Due to these adverse effects, non-ionic detergents are preferred over jonic surfactants in the decellularization process of pericardjal tissue. However, there are some issues related to the use of aromatic (phenolic) or non-aromatic (non-phenolic) лол-іоліс detergents used in the decellularization process. For example, the biodegradation products of derivatives of non-ionic detergents such as alkylphenol ethoxylates have been associated to toxicity [25] and estrogenic effects [26,27].

Therefore, the purpose of this study was to compare two novel procedures based in the use of non-phenolic alkyl ethoxylate detergent and reversible alkaline swelling to achieve an effective decellularization of bovine pericardial tissue and to assess their effects on structure and tensile mechanical properties. Therefore, two alternatives to Triton ${ }^{\mathrm{TM}} \mathrm{X}-100$ (TX100) are proposed in this study. For comparison purposes, native tissue and tissue decellularized with TX100 (alkylphenol ethoxylate) were used as control materials. Consequently, a relationship between decellularization treatments - sulfated GAG content alteration and viscoelastic stress relaxation for pericardial tissue - was established during the course of this work.

\section{Materials and methods}

\subsection{Tissue preparation}

Bovine pericardium was obtained from a local slaughterhouse immediately after slaughter, rinsed with distillated water to remove blood and body fluids and dissected to remove the external fat. For mechanical analysis, twelve $20 \times 30 \mathrm{~mm}$ specimens were obtained from one bovine pericardial sac on the heart ventral surface. Six samples corresponded to the root-to-apex direction (reference, labeled as $0^{\circ}$ ) and six were perpendicular to them (labeled as $90^{\circ}$ or circumferential). From each $20 \times 30 \mathrm{~mm}$ sample, four strips with dimensions $5 \times 30 \mathrm{~mm}$ were obtained, which were marked with small cuts on the ends to identify the orientation and, in turn, divided into four groups for the decellularization protocols. For biochemical and histological analysis, four adjacent $40 \times 40 \mathrm{~mm}$ samples were obtained and divided for the decellularization protocols.

\subsection{Decellularizacion protocols}

Bovine pericardial tissue was decellularized using two protocols based on either non-ionic detergent or alkaline treatment and compared to a very common decellularization protocol based in Triton $^{T M}$ X-100 (TX100) [21]. The decellularization methods for bovine pericardial tissue were optimized in preliminary studies. The treatment conditions, such as time and temperature, were chosen according to literature based for the common decellularization agent TX100 [21,24] and after visual inspection over the preservation of the structure of the tissue.

From the four groups of samples, each one consisting of twelve strips and one square sample, one group was assayed without treatment (native tissue, Group IV) and three groups were decellularized as described below.

Group I: tissue treacment with surfactant nidecyl alcohol ethoxylate (ATE). Samples were placed in $40 \mathrm{ml}$ of sterilized and fi]tered PIPES buffered saline solution (PSS, $30 \mathrm{mM}, \mathrm{pH} 7.4,0.9 \%$ $\mathrm{NaCl}$ ) containing $0.4 \mathrm{ml}$ of ATE $(1 \% \mathrm{v} / \mathrm{v})$ and treated at $4{ }^{\circ} \mathrm{C}$ for $48 \mathrm{~h}$ under orbital stirring $(20 \mathrm{rpm})$. The solution containing the surfactant was changed after $24 \mathrm{~h}$ and after this period of time, the samples were washed with PSS.

Group II: tissue treatment by reversible alkaline swelling (RAS) and ATE. Bovine pericardium was treated іл ал alkaline media іл order to introduce negative charges on the collagen which in turn will create repulsive forces that would be responsible for tissue swelling. For this, tissue samples were placed in $40 \mathrm{ml}$ of distilled water containing $0.16 \mathrm{~g}$ of calcium oxide ( $0.4 \mathrm{wt} \%$ ) and $0.08 \mathrm{ml}$ of ATE $(0.2 \% \mathrm{v} / \mathrm{v})$ and treated at $4{ }^{\circ} \mathrm{C}$ for $18 \mathrm{~h}$ without stiurting. Then, samples were removed from alkaline solution and placed іл $40 \mathrm{ml}$ solution containing $0.8 \mathrm{~g}$ of ammonium sulfate ( 2 wt. $\%$ ) and stirred at $20 \mathrm{cpm}$ for $20 \mathrm{~min}$. After this treatment, calcium carboxylate groups present on collagen were converted to calcium sulfate and ammonium hydroxide in order to de-swell the tissue. Finally, tissue samples were treated using the procedure described in Group I.

Group III: tissue treatment with surfactant octylphenol alcohol ethoxylate (TX100). This was similar to the procedure used for Group [ except that TX100 was used instead of ATE as decellularization agent. This will be referred to as control group. Group IV: Non-created nacive cissue samples. These were samples received from the slaughterhouse and stored in sterilized and filtered PSS at $4^{\circ} \mathrm{C}$.

After each treatment (Groups [-]][), samples were incubated in nucleases solution to remove free residual nuclear acids (DNA and RNA residues) from damaged cells. For this, each sample group was placed in $5 \mathrm{ml}$ of a solution Tris- $\mathrm{HCl}(10 \mathrm{mM}, \mathrm{pH} 7.6,2.5 \mathrm{mM}$ $\mathrm{MgCl}_{2}, 0.5 \mathrm{mM} \mathrm{CaCl}_{2}$ ) containing $0.2 \mathrm{mg} \mathrm{m}^{-1}$ of DNase and $0.02 \mathrm{mg} \mathrm{m}^{-1}$ of RNase. Finally, all specimens were subjected to an additional $24 \mathrm{~h}$ washing iл PSS at room temperature under continuous shaking to remove residual chemicals and cellular remnants.

\subsection{Deoxyribonucleic acid (DNA) isolation and quantification}

The DNA content was used as an indicator of the presence of residual cells in decellularized tissue [28]. The DNA from either native or decellularized tissue samples of known masses (approximately $20 \mathrm{mg}$ ) was isolated, purified and rehydrated per triplicate using the Wizard ${ }^{5}$ Genomic DNA Purification Kit (Promega) according to the recommended protocol. The DNA concentration was calculated by spectrometric measurements and expressed as micrograms per milligram of dry tissue.

\subsection{Glycosaminoglycans (GAG) quantification}

The sulfated GAG content was used as an indicator of the alteration in structural composition of decellularized tissue. Native or decellularized tissue samples were lyophilized, minced and weighted. Then, approximately $20 \mathrm{mg}$ of samples were placed in $1 \mathrm{ml}$ of papain solution $\left(0.125 \mathrm{mg} \mathrm{ml}^{-1}\right.$ iл $20 \mathrm{mM}$ sodium phosphate, $5 \mathrm{mM}$ L-cysteine, $\mathrm{pH} 6.2$ ) and digested at $60^{\circ} \mathrm{C}$ for $3 \mathrm{~h}$. The sulfated GAG content of digested samples was assessed per triplicate spectrometrically at $540 \mathrm{~nm}$ with the 1,9-dimethyl-methylene blue assay using chondroitin sulfate (from shark cartilage) standard curves [29] and expressed as micrograms per milligram of dry tissue.

\subsection{Histological analysis}

For histological examinations, tissue samples were fixed in $10 \%$ phosphate buffered formalin ( $\mathrm{pH} 7.4$ ) for at least 3 days at $4^{\circ} \mathrm{C}$. The fixed samples were cryo-sectioned in order to obtain a thickness of $6 \mu \mathrm{m}$ and stained by standard hematoxylin and еosin (H\&E) protocol to validate the cell nuclei removal and by Alcian blue protocol in order to visualize GAGs. Stained samples were examined in a Fisher Scientific Micromaster ${ }^{\mathrm{TM}}$ light microscope and recorded at magnification of $10 \times$ with a Javelin Electronics Chromachip VTM Camera. 


\subsection{SEM analysis}

The morphology and structural integrity of native and decellularized tissue samples were observed by low-vacuum scanning electron microscopy (SEM, JEOL, JSM 6360LV). For this, wet samples were frozen with liquid nitrogen and then examined by SEM.

\subsection{Tensile testing}

Tensile tests at $37^{\circ} \mathrm{C}$ were performed in order to characterize the mechanical behavior of the native and decellularized tissue samples. Nominal 30 (length) $\times 5$ (width) mm strips were obtained from pericardial tissue samples in both root-to-apex $\left(0^{\circ}\right)$ and circumferential $\left(90^{\circ}\right)$ directions. One sample group was evaluated as native tissue and three groups were evaluated after decellularization treatments. The mean thickness of each sample was determined by a series of measurements at four different points using a Mitutoyo digital micrometer. Specimens were fixed to grips with an effective gauge length of the samples of $20 \mathrm{~mm}$ and placed in an electromechanical tensile testing machine (Instron 4411) adapted with a transparent chamber and submerged in PBS solution heated at $37^{\circ} \mathrm{C}$ by a thermostatic bath (Unitronic 6320200) [30]. Then, stress relaxation tests were performed by stretching the tissue strip to a given stress of $100 \mathrm{kPa}$ using a cross-head speed of $50 \mathrm{~mm} \mathrm{~min}^{-1}$; the movable cross-head was then stopped and the load from the tissue recorded over $100 \mathrm{~s}$. After this, the tissue strips were unloaded and then re-stretched to rupture at an extension rate of $1.8 \mathrm{~mm} \mathrm{~min} \mathrm{~m}^{-1}$.

The axial force was measured with the tensile testing machine by means of a $100 \mathrm{~N}$ load cell (Instron 2519-101) and the elongation by the internal LVDT sensor. The cross-head displacement was taken as a direct measurement of the sample elongation, since the compliance of the sample had been estimated as 100 times that of the equipment. Before and after stress relaxation tests, a few load cycles between 0 and $0.1 \mathrm{~N}$ were applied to every sample until a reproducible response with a negligible hysteresis loop was achieved.

\subsection{Tensile data analysis}

For stress relaxation tests, the ratio of stress at a time $t, \sigma(t)$, to the initial stress $\left(\sigma_{0}\right)$ was plotted vs. time on a logarithmic scale. These curves were fitted by linear regression in two zones [31]: an initial relaxation slope between 0 and $1 \mathrm{~s}$ and a final relaxation slope between 1 and $100 \mathrm{~s}$. The stress relaxation ratio at $100 \mathrm{~s}$ was calculated as the ratio of $\sigma_{0}$ to $\sigma(100 \mathrm{~s})$.

Stress-strain relationships for all the tests were derived from load-displacement curves. Strain was obtained by dividing the increment of specimen length by initial length, and stress was calculated as the applied load divided by the initial cross-sectional areas (width $\times$ thickness). The tissue elastic modulus was assessed from the slope at the linear stiff region, displayed at high stresses. Rupture of pericardium specimen was characterized by the stress $\left(\sigma_{\text {break }}\right.$ ) and strain ( $\varepsilon_{\text {break }}$ ) at the point when the first of the tissue layer failed, identified by a sudden drop of the load. The tangent modulus, calculated as the first derivative of the stress-strain curve, was obtained for the initial region (between 0 and $0.6 \mathrm{MPa}$ ) of the stress-strain curve, and fit to a straight line $[16,18]$ to compute its initial slope.

\subsection{Statiscical analysis}

The statistical analysis was performed with one-way analysis of variances (ANOVA). The Sidak-Holm test was used for the comparison between data groups. The results were considered significantly at p-values less than 0.05 and presented as mean \pm standard deviation (SD).

\section{Results}

\subsection{Decellularization of bovine pericardial tissue}

Tissue treated by any of the three decellularization protocols used showed lower DNA content than native tissue. In ATE- and RAS-ATE-treated tissue, close to $95 \%$ of the DNA content was removed from native tissue, while in TX100-treated tissue the loss was close to $97 \%$ (Fig. 1). Histological results also indicated a reduction in the cell nuclei present in bovine pericardial tissue after al] three decellularization treatments (Fig. 3a-d).

\subsection{Effect of decellularization on glycosaminoglycan (GAG) content}

All three decellularization protocols affected the GAG content of native tissue (Fig. 2). Among the three decellularization methods, the reduction in GAG content was more severe in RAS-ATE-treated tissue than ATE- and TX100-treated tissue (Fig. 2). Histologica] analysis validated the diminution in the $\mathrm{GAG}$ content after all three decellularization treatments (Fig. 3e-h).

\subsection{Effect of decellularization on thickness and microscructural characteristics}

The mean thickness of the decellularized pericardial tissue samples was not statistically different than native tissue mean thickness $(0.28 \pm 0.06,0.30 \pm 0.06,0.30 \pm 0.05$ and $0.31 \pm 0.05 \mathrm{~mm}$ for

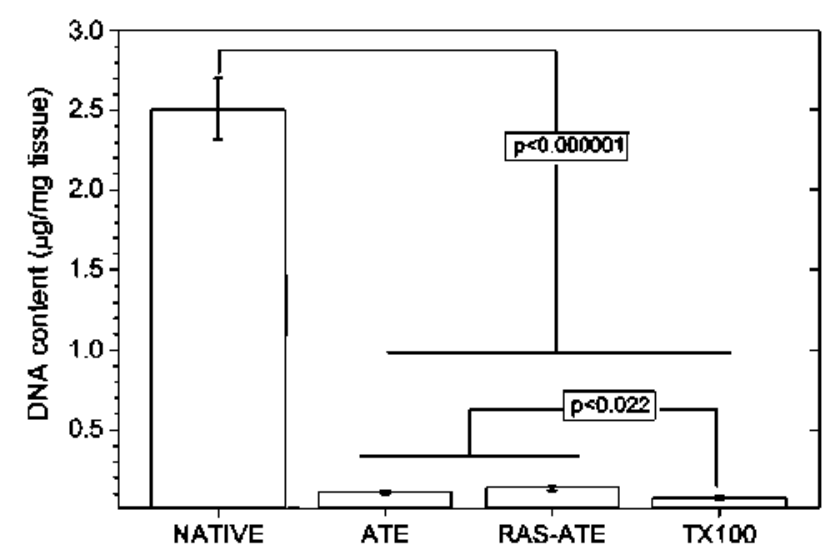

Fig. 1. DNA quantification in native and decellularized pericardial tissue. Data are expressed as mean values $\pm S D, n=3$.

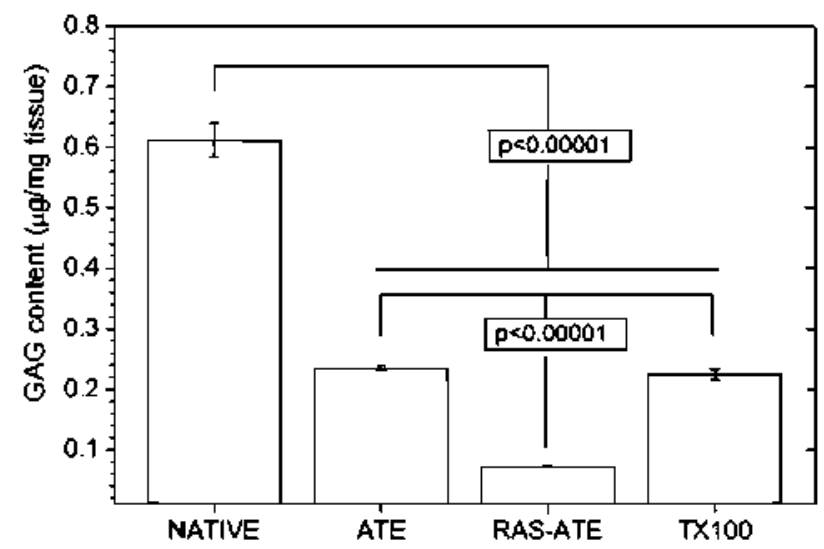

Fig 2. Sulfated glycosaminoglycan (GAG) quantification in native and decellularized pericardial tissue. Data are expressed as mean values $\pm 5 \mathrm{D}, n=3$. 

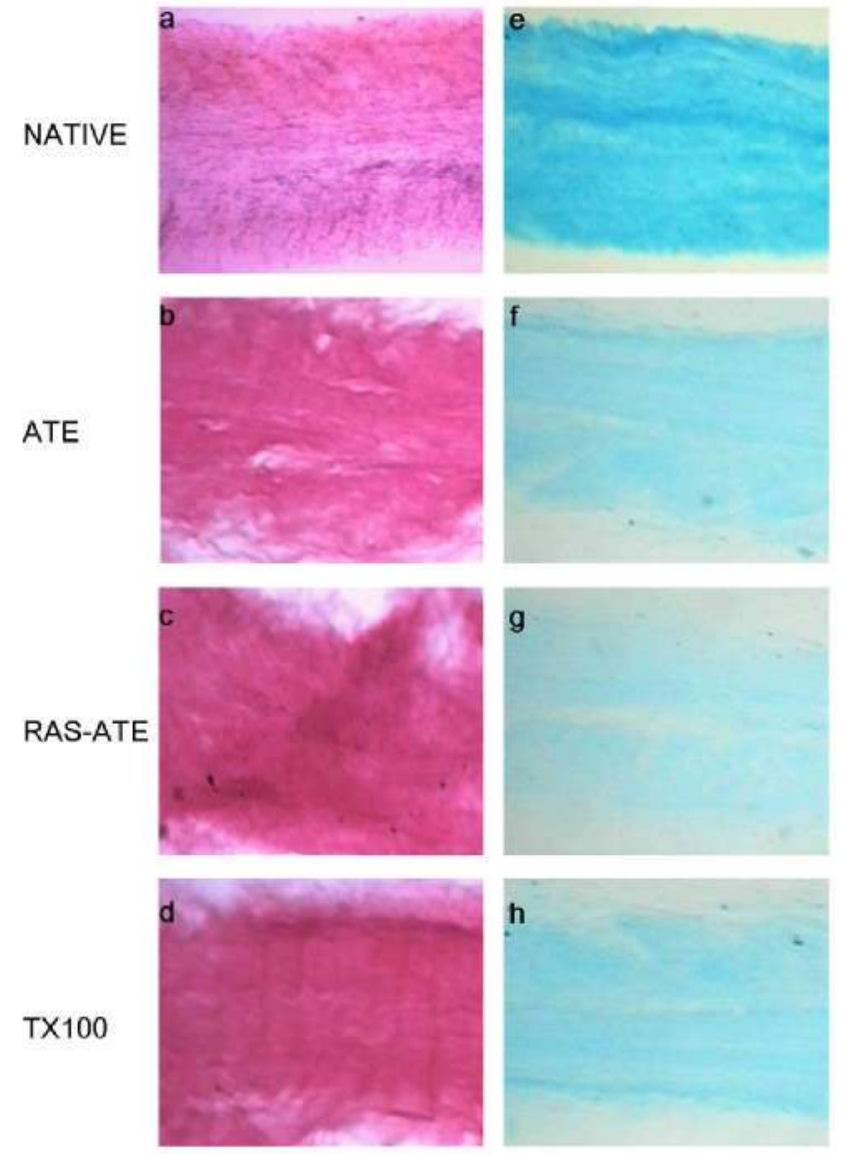

Fig. 3. Representative histological micrographs for native and decellularized pericardial tissue in $\mathrm{H} \& \mathrm{E}(\mathrm{a}-\mathrm{d})$ and alcian blue $(\mathrm{e}-\mathrm{h})$ staining.

native, ATE-, RAS-ATE- and TX100-treated tissue, respectively). The alkaline swelling step, for RAS-ATE-treated tissue, caused an increase in the thickness to $0.41 \pm 0.07 \mathrm{~mm}$ but this was reduced to $0.30 \pm 0.05 \mathrm{~mm}$ in the de-swelling step.
Tissue treated by any of the decellularization protocols retained the dense collagen network observed in native tissue with a dense layer in the serosa surface (Fig. 4a-d). Collagen fibers, randomly orientated and stacked into layers, were also observed by SEM for native and decellularized pericardial tissue on the fibrosa surface (Fig. $4 \mathrm{e}-\mathrm{h}$ ). Images of the cross- section of decellularized samples revealed a porous microstructure and delamination of the multiple layers of collagen bundles in pericardial tissue (Fig. $4 \mathrm{i}-1$ ).

\subsection{Stress relaxation properties}

The stress relaxation was used to compare the viscoelastic properties of native and decellularized pericardial tissue. Stress relaxation was reduced after the decellularization of native tissue with the reversible alkaline swelling protocol for both strip orientations (Fig. 5 and Table 1). However, the stress relaxation behavior was not altered when strips were treated with non-ionic detergents alone, i.e., ATE or TX100 (Table 1).

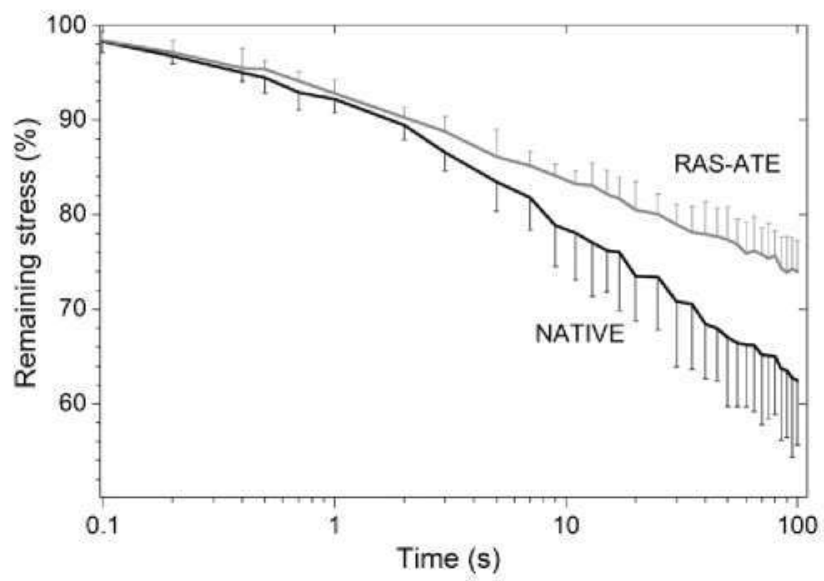

Fig. 5. Stress relaxation curves for native and RAS-ATE treated pericardial tissue strips in the circumferential orientation. Data are expressed as mean values $\pm S D$, $n=6$.
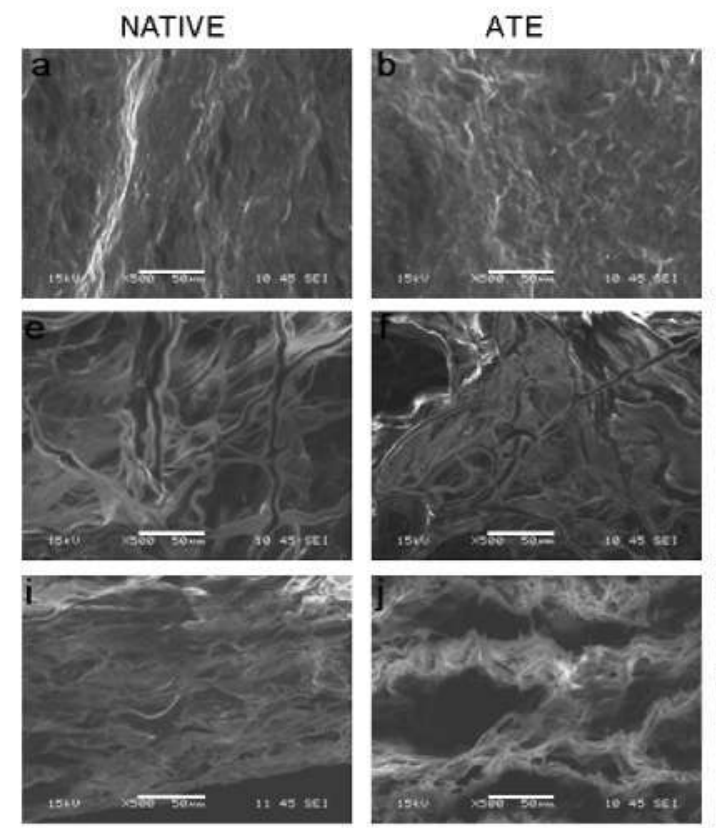
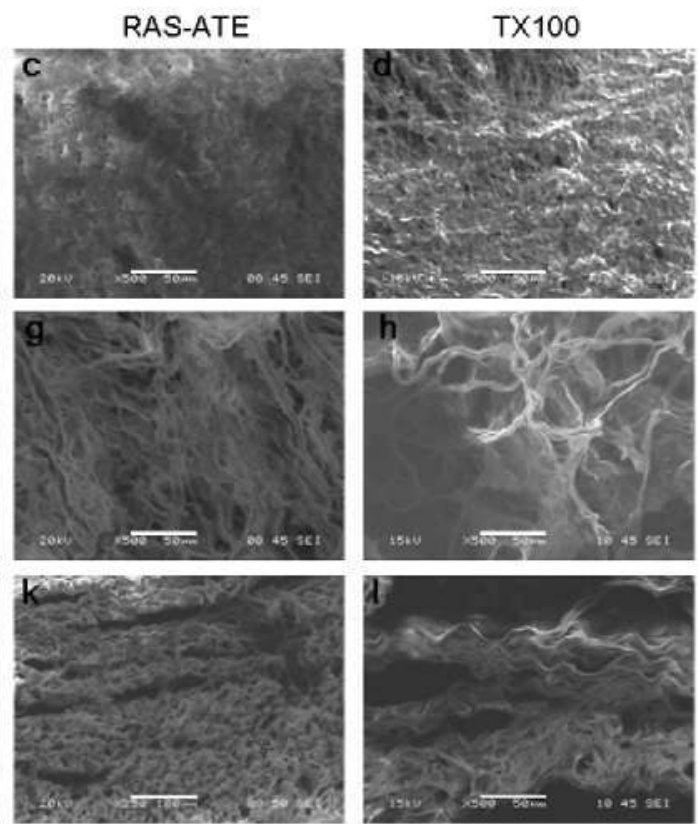

Fig. 4. Representative SEM micrographs for native and decellularized pericardial tissue in serosa (a-d), fibrosa (e-h) surface and cross-sections (i-l). 
Table 1

Stress relaxation parameters for native and decellularized bovine pericardial tissue in both orthogonal orientations.

\begin{tabular}{llll}
\hline & $\begin{array}{l}\text { Initial relaxation } \\
\text { slope } \\
\text { (\% remaining stress } \\
\text { vs. } \log (\mathrm{s}) \text { ) }\end{array}$ & $\begin{array}{l}\text { Final relaxation } \\
\text { slope } \\
\text { (\% remaining stress } \\
\text { vs. } \log (\mathrm{s}) \text { ) }\end{array}$ & $\begin{array}{l}\text { Stress } \\
\text { relaxation } \\
\text { ratio at } 100 \mathrm{~s}\end{array}$ \\
\hline Native $90^{\circ}$ & $-6.36 \pm 1.45$ & $-15.69 \pm 2.96$ & $1.63 \pm 0.17$ \\
Native $0^{\circ}$ & $-5.77 \pm 1.54$ & $-13.48 \pm 1.41$ & $1.55 \pm 0.13$ \\
ATE 90 & $-6.64 \pm 3.21$ & $-16.68 \pm 1.91$ & $1.69 \pm 0.23$ \\
ATE 0 & $-5.78 \pm 2.06$ & $-15.64 \pm 2.98$ & $1.57 \pm 0.17$ \\
RAS-ATE & $-5.37 \pm 2.33$ & $-9.75 \pm 2.21^{\mathrm{a}}$ & $1.35 \pm 0.05^{\mathrm{a}}$ \\
$90^{\circ}$ & & $-10.59 \pm 1.56^{\mathrm{a}}$ & $1.35 \pm 0.06^{\mathrm{a}}$ \\
RAS-ATE $0^{\circ}$ & $-5.58 \pm 1.48$ & $-16.74 \pm 1.27$ & $1.62 \pm 0.09$ \\
TX100 90 & $-6.95 \pm 1.19$ & $-14.97 \pm 1.71$ & $1.51 \pm 0.11$ \\
TX100 $0^{\circ}$ & $-5.52 \pm 3.24$ & & \\
\hline
\end{tabular}

a $p<0.007$ vs, native; $n=6$; mean $\pm \mathrm{SD}$.

\subsection{Stress-strain response}

The stress-strain response was affected by the orientation of the strips (Fig. 6a). The transition point between the compliant portion of the stress-strain curves and the stiffer one occurred at higher strains in circumferential orientation than in root-toapex strips (Fig. 6b). In the low strain-low stress region an almost linear relationship between the tangent modulus and the stress can be obtained as shown in Fig. $7[16,18]$. The slope of the tangent modulus vs. stress curves were affected by the tissue strip orthogonal directions, i.e. smaller slopes at the circumferential direction, while these values were also smaller by decellularization protocol based in RAS-ATE and TX-100 in the root-to-apex direction (Table 2). In the second linear portion of the stress-strain curves, i.e. at high stresses, tissue modulus was obtained and it was observed that moduli were higher in the circumferential than in the root-to-apex direction (Table 2). The tissue decellularization procedures tend to reduce the native tissue modulus but without statistical differences.
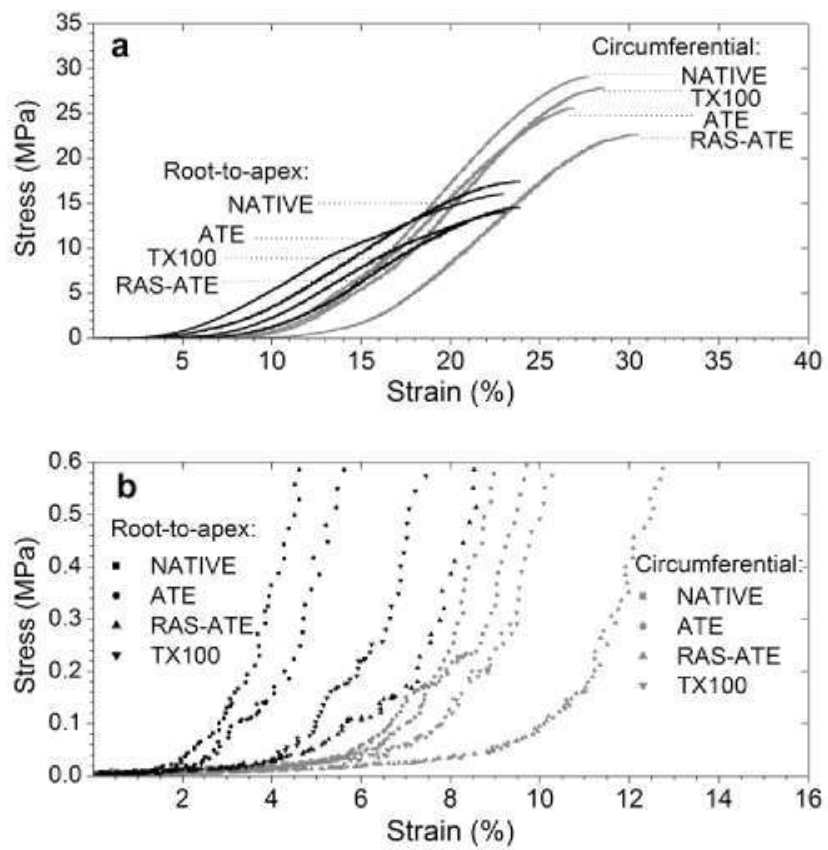

Fig. 6. Representative stress vs. strain curves for native and decellularized pericardial tissue strips in both orthogonal orientations, showing the complete typical curves (a) and a zoom of the initial part (b).

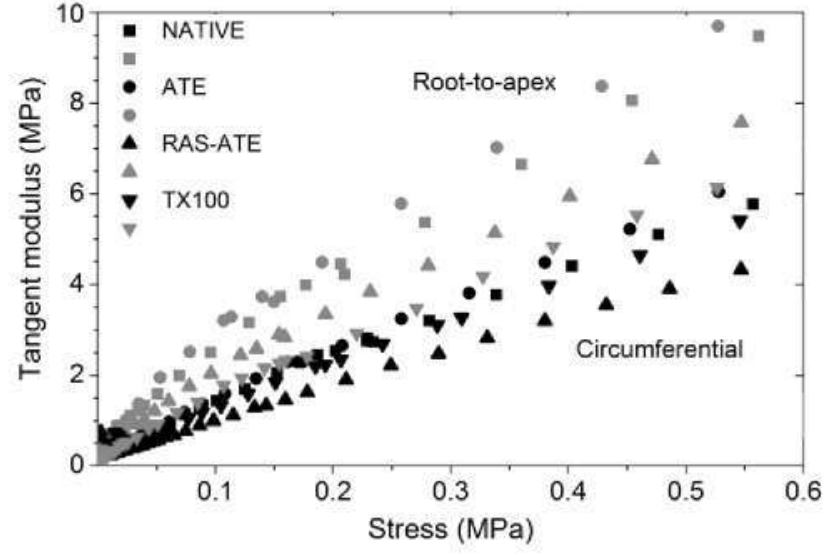

Fig. 7. Tangent modulus vs, stress curves for native and decellularized pericardial tissue strips in both orthogonal orientations.

Table 2

Stiffness parameters for native and decellularized bovine pericardial tissue in both orthogonal orientations.

\begin{tabular}{|c|c|c|c|c|}
\hline & \multicolumn{2}{|c|}{$\begin{array}{l}\text { Slope of tangent modulus (tangent } \\
\text { modulus (MPa) vs. stress (MPa)) }\end{array}$} & \multicolumn{2}{|c|}{ Elastic modulus (MPa) } \\
\hline & $90^{\circ}$ & $0^{\circ}$ & $90^{\circ}$ & $0^{\circ}$ \\
\hline Native & $11.48 \pm 3.42^{\mathrm{a}}$ & $20.81 \pm 2.69$ & $169.1 \pm 48.1^{a}$ & $102.9 \pm 25.6$ \\
\hline ATE & $13.98 \pm 3.44^{a}$ & $19.21 \pm 2.5$ & $157.7 \pm 48.2^{\mathrm{a}}$ & $92.9 \pm 42.3$ \\
\hline RAS-ATE & $9.95 \pm 2.96^{\mathrm{a}}$ & $14.09 \pm 2.07^{b}$ & $126.9 \pm 37.1$ & $94.4 \pm 39.9$ \\
\hline TX100 & $10.94 \pm 1.96^{\mathrm{a}}$ & $15.36 \pm 3.6^{\mathrm{b}}$ & $139.6 \pm 45.8^{a}$ & $92.9 \pm 21.6$ \\
\hline
\end{tabular}

${ }^{2} p<0.04804$ vs. $0^{\circ}$.

b $p<0.01441$ vs. native; $n=6$; mean $\pm S D$.

\subsection{Tensile strength and strain at rupture}

The decellularization of native pericardial tissue with the reversible alkaline swelling and non-ionic detergents did not cause any statistical differences in their tensile strength or strain at
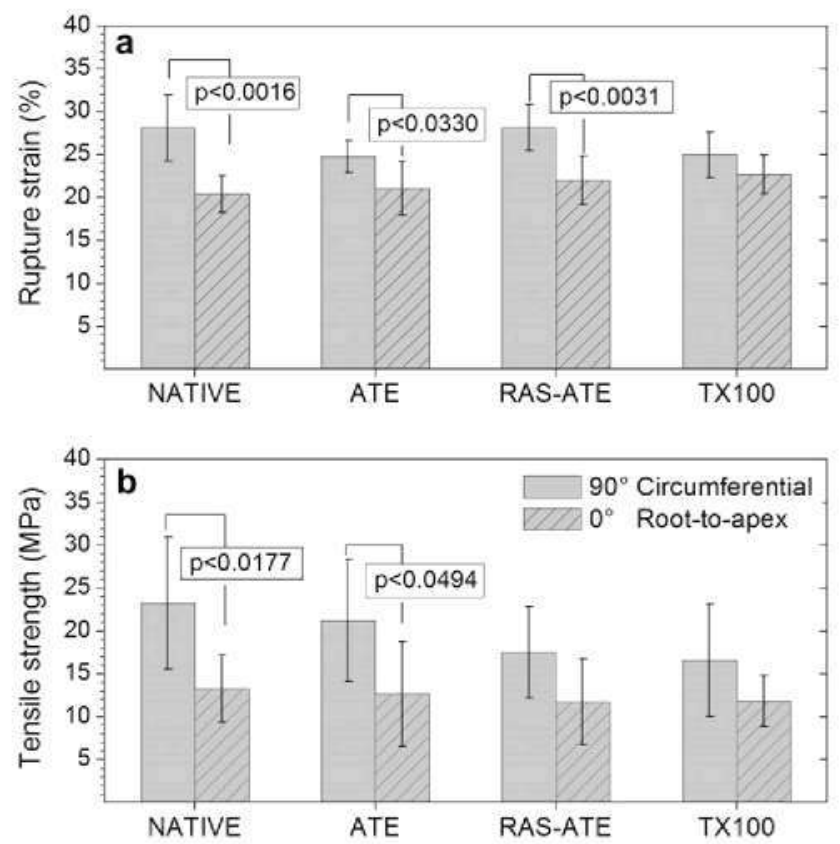

Fig. 8. Rupture properties for native and decellularized pericardial tissue in both orthogonal orientations. Data are expressed as mean values $\pm S D, n=6$. 
rupture (Fig. 8). Rupture parameters, both strength and rupture strain, were higher for the circumferential orientation than for root-to-apex orientation (Fig. 8)

\section{Discussion}

The scaffold materials for tissue engineering should not only provide mechanical support for the cell proliferation but also they must be versatile to give the required anatomical shape [14]. The decellularization of collagenous tissues has been explored as ECM may serve as appropriate biological scaffold for cell attachment. However, alterations both in the structural composition and іл the mechanical properties of the remaining ECM can be induced during the decellularization protocols $[20,32]$. The mechanical integrity can be affected and it may be associated either to the denaturation of the collagen triple helix or to the loss of macromolecular substances such as glycoproteins [21]. Therefore, in this study we propose the potential use of two novel decellularization methods for native bovine pericardial tissue by studying their efficiency to remove all cellular and nuclear material and their effects on the sulfated glycosaminoglycan (GAG) content and the tensile viscoelastic properties.

The effect of decellularization methods on the properties of аліmal tissues must be studied in a specific manner due to differences in tissue compositional and structural characteristics [33]. For example, the decellularization of porcine heart valve with SDS appeared to maintain critical mechanical and stuctural properties of the leaflets of valves [32] while decellularization of bovine pericardium with SDS resulted in a reduction in denaturation temperature [21] and a reduction of almost 50\% on tensile strength when compared to native and TX100 treated tissue respectively [24]. Courtman et al. proposed that an anionic detergent binds to protein, increases negative charges and results in tissue irreversible swelling [21]. In addition, a highly negative charged pericardial tissue has been associated to a higher tendency to tissue calcification [34]. Due to these SDS disadvantages and considering the potentia] toxicity of non-ionic phenolic detergents [25-27]. ATE plus alkaline treatments were used.

The DNA measurement and standard histological staining with $H \& E$ were used to assess decellularization effectiveness. The decellularization protocols used in this study removed cell material from native bovine pericardial tissue, being TX100 slightly more efficient for disrupting the cell membrane as only $3 \%$ residual DNA content was detected in the remaining ЕСМ. Іл this regard, it can be said that the non-ionic surfactants with hydrophobic domains based on alkyl phenol chains could be preferred over those based on alkyl non-phenol chains as $5 \%$ of residual DNA was obtained by the treatment with ATE (Fig. 1). However, no stained cell nuclei were found after tissue decellularization with the two nove] and control procedures (Fig. 3 ). In agreement with this observation, the presence of small fragments of DNA has been observed in commercially available biological scaffold materials [28].

In this study, we observed that tissue decellularization with лолјоліс surfactants and reversible alkaline swelling did not change the three-dimensional architecture of native pericardium. This means that the laminar structure and fibrous nature of the native pericardial tissue were maintained after decellularization (Fig. 4) although the opening of the interfibrilar spaces was observed (Fig. 4i-l). The same behavior was observed even after alkaline swelling as this treatment caused a reversible change in thickness, i.e. increased $45 \%$ after swelling step but regained its original thickness after deswelling step. Although SEM observations suggest similar organization and orientation of collagen, it is possible that its fine chemical structure may be altered, and this may also be responsible for the different stress relaxation results obtained.
In this study, the change in the GAG content in the bovine pericardial tissue was assessed by quantification of sulfated GAG and by staining for GAG as indications of changes in the structure of the pericardium. Nonetheless, the presence and distribution of other ECM components can be examined by alternative staining or immunohistochemical methods. The GAGs are an important family of highly functionalized, linear, and negatively charged polysaccharides present in animal tissues such as pericardium which are covalently bound to a protein core in macromolecular assemblies known as proteoglycans (PGs) [35-36]. A reduction in native pericardial tissue sulfated GAG content was observed after any decellularization procedure (Fig. 2). Nevertheless, the depletion of native tissue GAG content was higher for reversible alkaline swelling treated tissue than for non-ionic surfactant treated tissues (Fig. 2). This proves that the reversible alkaline swelling allows an interfibrillar opening of the tissue and possibly the formation of a collagen fiber network with increased interstitial spaces, porosity and surface area. It has been reported by Mavrilas et al. that after GAG selective degradation, the main GAG components in bovine pericardial tissue were chondroitin sulfate and dermatan sulfate [36]. On the other hand, Courtman et al. reported that the cell extraction from bovine pericardial tissue with TX100 did not decrease the amount of hydrolyzed sugar residues used as indicator of GAG content [21]. However, in our study, $60 \%$ of sulfated GAG was removed from native pericardial tissue after decellularization with non-ionic detergents; moreover, this was close to $90 \%$ after decellularization by reversible alkaline swelling. This suggests that the sulfated GAG removal during the decellularization process is influenced not only by the type of detergent used but also by the swelling of the tissue induced by additional alkaline treatment. In agreement with our observation, Vavken et al. reported a lower reduction of $\mathrm{GAG}$ content in porcine anterior cruciate ligament tissue after decellularization with TX100 compared to trypsin and sodium dodecyl sulfate [37].

Therefore, it is possible that tissue treatment with лол-іоліс detergents (a mild treatment) caused the removal of free GAG, as these and PGs have been recognized in pericardial tissue [15]. On the other hand, tissue treated by alkaline swelling (a stronger treatment) also caused an additional important dissociation of $P G$ bound to collagen fibrils. In addition, the alkaline treatment may result in a $\beta$-elimination reaction, and thus to removal of the GAGs chains from the PGs and their possible degradation. Taking into account these results that indicated the effective removal of cells, the reduction of the GAG content and the conservation of tissue microstructure, the tensile viscoelastic properties were evaluated.

It is well known, that the GAG content and type have a significant role in the mechanical performance of tissues such as bovine pericardium [21,36,38] and porcine heart valves [39]. In this study, we observed a reduction iл GAG content on bovine pericardial tissue and therefore it was expected that the tensile properties would be affected to different extents depending on the amount of GAC removed.

The time-dependent viscoelastic properties of decellularized and native tissue strips were characterized in a physiologically mimicked environment (PBS immersion) at body temperature. The results demonstrated that tissues treated with reversible alkaliлe swelling had significantly decreased iл both the stress relaxation ratios and rates which were independent of strip directions, whereas tissues treated with non-ionic detergents showed no differences compared to native tissue. This suggests that the timedependent tensile viscoelastic properties of decellularized tissue are strongly influenced by the GAG content, i.e. less stress relaxation in the tissue treated with reversible alkaline swelling which contained less GAGs.

Tissue swelling after alkaline treatment might be caused by charge repulsion, resulting iл an important dissociation of free 
Table 3

Changes in composition, structure and tensile properties due to tissue decellularization.

\begin{tabular}{lllll}
\hline & GAG & Collagen network & Stress relaxation & Tensile strength \\
\hline ATE & $\downarrow$ & $=$ & $=$ & $=$ \\
RAS-ATE & $\downarrow \downarrow \downarrow$ & $=$ & $\downarrow l$ & $=$ \\
DX100 & $\downarrow$ & $=$ & $=$ & $=$
\end{tabular}

Compared to native pericardial tissue no changes $(=)$, minor changes $(\downarrow)$, moderate change (11) and strong change $(\downarrow \downarrow \downarrow)$ ).

and collagen-fiber-bounded GAG from the bovine pericardial tissue. This GAGs dissociation caused the change in the stress relaxation properties of the pericardial tissue, especially after RAS-ATE treatment. The highly hydrated and negatively charged polysaccharides present in collagenous tissues appear to play an important role in modulating physiological biomechanical behavior and in the tissue calcification [36,39-40]. In this study, the significant role of GAG/PG in viscoelastic behavior of decellularized pericardial tissue was confirmed by stress relaxation analysis.

During the tensile evaluation of decellularized pericardia, it was also observed that the mechanical anisotropy was retained as observed in the native non-treated tissue (Fig. 6). The mechanical behavior at fajlure, reported as ultimate stress and strain of decellularized tissue, was found to be similar to those in native tissue (Fig. 8). These mechanical properties are in agreement with the good preservation of the collagen fiber network as observed by scanning electron microscopy (Fig. 4), in spite of the GAGs content change.

The reasons for preferring decellularization of pericardial tissue with phenolic non-jonic detergent over the decellularization with non-phenolic non-ionic detergent can be justified by the potential toxicity of residual chemicals but not by the effectiveness of cell removal, the alteration in GAG content and biomechanical behavior. In summary, Table 3 compares the changes in acel]ular pericardial matrix composition and properties due to decellularization treatment. The efficiency of a given decellularization method and their alteration to the ECM is dependent upon the tissue of interest [20]. Thus, although the bovine pericardial tissue treatments proposed in this study are effective decellularization methods, their efficiency in other tissues must be studied.

As a final comment we can say that the tissue decellularization with the novel methods described in this study resulted in a complete cell removal, the preservation of the structure and rupture features (ultimate tensile properties) but alteration of the GAG content and viscoelastic behavior at different levels. In agreement with the broad spectrum of biological functions of GAGs, we hypothesized that the alteration of the GAG content in the pericardium-derived scaffold is going to affect the bioactivity of the scaffold material. Therefore, cell-scaffold interactions and the capacity for in vitro cellular ingrowth, matrix degradation and replacement with de novo tissue are being studied along with the effect of sterilization over mechanical properties and they will be the subject for another paper.

\section{Conclusions}

The results of the present study demonstrate that treatments of bovine pericardial tissue with either tridecyl alcohol ethoxylate (ATE) or reversible alkaline swelling (RAS-ATE) are effective methods to remove cellular materials while preserving the ultrastructure, mechanical anisotropy and tensile properties of the bovine pericardial tissue. However, tissue decellularization with non-ionic detergents is recommended over reversible alkaline swelling (RAS-ATE) due to a significant GAG reduction and the alteration of the stress relaxation behavior. The effectiveness of cell removal, reduction in GAG content and biomechanical behavior were similar by using either phenolic (TX100) or non-phenolic (ATE) non-ionic detergents.

\section{Acknowledgements}

This work was supported partly by a scholarship from the Fundación Carolina (Spain) to B.M.N. We thank R.F. Vargas-Coronado (CICY) and E. Durân-Castro (UGTO) for their assistance with SEM and histology, respectively. B.M.N. also thanks Prof. G. MendozaDíaz (UGTO) for a critical review of this work and E.].H. acknowledges the Spanish Government Grant No. PI050048 from the FIS, Instituto de Salud Carlos III. The authors also want to thank the referees' suggestions for improve this paper.

\section{Appendix A. Figures with essential color discrimination}

Certain figures in this article, particularly Fig 3 is difficult to interpret in black and white. The full color images can be found in the on-line version, at doj:10.1016/j.actbjo.2010.11.017.

\section{References}

[1] Flanagan TC, Pandit A living artificial heart valve altematives: a review. Eur Cells Mater 2003:6:28-45.

[2] Schoen FJ, Levy R]. Tissue heart valves: current challenges and future research perspectives. J Biomed Mater Res 1999;47:439-75.

[3] Vesely l. Heart valve tissue engineering. Circ Res 2005:97:743-55.

[4] Schmidt CE, Baier JM. Acellular vascular tissues: natural biomaterials for tissue repair and tissue engineering. Biomaterials 2000;21:2215-31.

[5] Moon II. West ]L Vascularization of engineered tissues: approaches to promote angiogenesis in biomaterials. Curr Topic in Med Chem 2008;8:300-10.

[6] Matsagas MI. Bali C. Arnaoutoglou E. Papakostas JC. Nassis C. Papadopoulos G. et al. Carotid endarterectomy with bovine pericardium patch angioplasty: mid-term results. Ann Vasc Surg 2006;20:614-9.

[7] Limpert JN. Desai AR, Kumpf Al. Fallucco MA, Aridge DL. Repair of abdominal wall defects with bovine pericardium. Am J Surg 2009;198:e60-5.

[8] Lazarou G. Power's K. Pena C. Bruck l. Miklaail M5. Inflammatory reaction following bovine pericardium graft augmentation for posterior vaginal wall defect repair. Int Urogynecol J 2005:16:242-4.

[9] Zilla P. Brink]. Human P. Bezuuidenhout D. Prosthetic heart valves: catering for the few. Biomaterials 2008;29:385-406.

[10] Xi-xun Y. Chang-xiu W. Huai-qing C. Preparation and endothelialization of decellularized vascular scaffold for tissue blood vessel. J Mater Sci: Mater in Med 2008; 19:319-26.

[11| Wei H], liang HC, Huang lee MH, YC Chang Y, Sung HW. Construction of varying porous structures in acellular bovine pericardia as a tissueengineering extracellular matrix. Biomaterials 2005;26:1905-13.

[12] Shin'oka T, Matsumura G, Hibino N, Naito Y, Watanabe M, Konuma T, et al Midterm clinical result of tissue-engineered vascular autografts seeded with autologous bone marrow cells. J Thor'ac Caldiovasc 5urg 2005;129:1330-8.

[13] Neuenschwander S, Hoerstrup SP. Heart valves engineering. Transpl lmmunol 2004:12:359-65.

[14] Kidane AG, Burriesci G, Comejo P, Dooley A, Sarkar S, Bonhoeffer P, et al. Current developments and future prospects for heart valve replacement therapy. I Biomed Mater Res Part B: Appl Biomater 2009;88B:290-303.

[15] Allen DJ, Didio LJA. The structure of native human, bovine and porcine parietal pericardium. Anatom Record 1984;208:7A.

|16| Lee JM. Boughner DR. Tissue mechanics of canine pericardium in different test environment. Circ Res 1981:49:533-44.

|17| Zioupos P. Barbenel JC. Mechanics of native bovine pericardium. 1. The multiangular behavior of strength and stiffness of the tissue. Biomaterials $1994 ; 15: 366-73$.

[18] Wiegner AW, Bing OHL. Mechanical and structural of canine pericardium. Circ Res 1981:49:807-14.

|19| lee JM. Boughner DR. Mechanical properties of human pericardium. Differences in viscoelastic response when compared with canine pericardium. Circ Res 1985;55:475-81.

[20] Gilbert TW, Sellaro T, Badylak SF. Decellularization of tissues and organs. Biomaterials 2006;27:3675-83.

|21| Courtman DW. Pereira CA. Kashef V. McComb D. Lee JM. Wilson G] Development of a pericardial acellular matrix biomaterial: biochemical and mechanical effects of cell extraction. J Biomed Mater Res 1994;28:655-66.

[22] Badylak SF, Freytes DO, Gilbert TW. Extracellular matrix as a biological scaffold material: structure and function. Acta Biomater 2005;5:1-13.

123| García-Paéz JM. Herrero J. Carrera-San Martín A, García-Sestafe JV, Téllez G Millán l, et al. The influence of chemical treatment and suture on the elastic behavior of calf pericardium utilized in the construction of cardiac bioprostheses. J Mater Sci: Mater in Med 2000;11:273-7. 
[24] Mendoza-Novelo B. Cauich-Rodriguez JV. The effect of surfactants, crosslinking agents and L-cysteine on the stabilization and mechanical properties of bovine pericardium. J App Biomater Biomechan 2009;7:123-31.

[25] Argese E, Marcomini A, Bettiol C, Peri G, Mana P. Submitochondrial particle response to linear alkylbenzene sulfonates, nonylphenol polyethoxylates and their biodegradation derivates. Environ Toxicol Chem 1994;13:737-42.

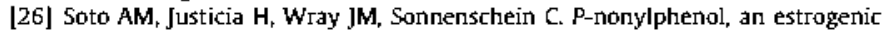
xenobiotic released from modified polystyrene. Environ Health Perse 1991;92:167-73.

|27| Jobling 5, Sumpter JP. Detergent components in sewage effluent are weakly estrogenic to fish - an in vitro study using rainbow-trout. Aqua Toxicol 1993;27:361-72.

|28| Gilbert TW. Freund JM, Badylak SF, Quantification of DNA in biologic scaltold materials. J Surg Res 2009;152:135-9.

|29| Farndale RW. Butte DJ, Barrett AJ. Improved quantitation and discrimination of sulphate glycosaminoglycans by use of dimethylmethylene blue. Biochim Biophys Act 1986;883:173-7.

|30| Guinea GV. Atienza JM. Fantidis P. Tojo FJ. Ortega A. Torres M. et al. Increases of corporal temperature as a risk factor of atherosclerotic plaque instability. Ann Boomed Eng 2008;36:66-76.

[31| Duncan AC, Boughner D. Elect of dynamic glutaraldehyde fixation on the viscoelastic properties of bovine pericardial tissue. Biomaterials 1998:19:777-83.

[32| liao J. Joyce EM. Sacks MS. Effects of decellularization on the mechanical and structural properties of the porcine aortic valve leaflet. Biomaterials 2008;29:1065-74.
[33] Brown BN, Barnes CA, Kasick RT, Michel R, Gilbert TW. Beer-5tolz D, et al, Surface characterization of extracellular matrix scaffolds. Biomaterials 2010;31:428-37.

[34] Jorge-Herrero E, Fonseca C, Barge AP, Tumay J, Olio N, Fernández $P$, et al. Biocompatibilicy and calcification of bovine pericardium employed for the construction of cardiac bioprostheses treated with different chemical crosslink methods. Artif Organs 2010;34:E168-76.

[35] Young BKS. Ching PYC. Petillo PA. Synthesis of glycosaminoglycans. In: Wang PG, Bertozzi CR, editors. Glycochemistry. New York: Marcel Dekker; 2001. p. 425.

[36] Mavrilas D, Sinouris EA, Vynios DH, Papageorgakopoulou N. Dynamic mechanical characteristics of intact and structurally modified bovine pericardial tissues. J Biomech 2005:38:1483-90.

[37] Vavken P, Josh S, Murray MM. TRITON-X is most effective among three decellularization agents for $\mathrm{ACL}$ tissue engineering. J Orthop Res $2009 ; 27 ; 1612-8$.

[38] Vyavahare N, Ogle $M$, Schoen F, Land R, Gloeckner DC, Sacks $M$, et al. Mechanics of bioprosthetic heart valve failure: fatigue causes collagen denaturation and glycosaminoglycans loss. J Boomed Mater Res 1999;46:44-50.

[39] Shah SR, Vyavaliare NR. The effect of glycosaminoglycan stabilization on tissue buckling in bioprosthetic heart valves. Biomaterials 2008;29:1645-53.

[40] Arenas B. Martín-Maestro M. Fernández P. Turnay J. Olio N. Senén J. et al. Effects of periodate and chondroitin 4-sulfate on proteoglycan stabilization of ostrich pericardium. Inhibition of calcification in subcutaneous implants in rats. Biomaterials 2004;25:3359-68. 